\title{
Sustainable Tourism: A Review of Indicators
}

\author{
Coverage: UK \\ Date: 10 October 2011 \\ Geographical Area: Local Authority and County \\ Theme: People and Places
}

\section{Sustainable Tourism: A Review of Indicators}

This report from the Tourism Intelligence Unit (TIU) at ONS details work undertaken to review and appraise current sustainable tourism indicators. This review has drawn on a wide range of examples of such indicators currently in use, from an international and domestic perspective. We present some possible sustainable tourism indicators that could be employed at the national and local levels but this does not represent an 'official' set of indicators but rather indicators that can be used as the basis for further discussions. Therefore, this represents an interim report from the TIU detailing the results of the review carried out. Following this report further work will be conducted to test the utility and application of suggested indicators which the TIU will report on in due course.

\section{Acknowledgements}

We wish to acknowledge the help of the English Tourism Intelligence Partnership, and the VisitEngland led Sustainable Tourism Action Group in providing feedback on earlier versions of this report.

\section{Introduction}

This report from the Tourism Intelligence Unit at ONS details work undertaken during 2010/11 that has been concerned with a review and appraisal of sustainable tourism indicators. This review has drawn on a wide range of examples of such indicators currently in use, from an international and domestic perspective.

The aim here, however, is not simply to highlight current best practice in the use of sustainable tourism indicators but rather to evaluate whether those indicators that exist within England and the UK, can be usefully employed to monitor sustainable tourism that are either in place or currently in development. This review includes an assessment of how individual indicators should be assessed in terms of how they meet the needs of particular stakeholder groups in tourism and, secondly, 
how indicators can be framed within an over-arching framework that allows for a comprehensive assessment of how they contribute to a holistic view of the variaous stages towards sustainable tourism development. That wide ranging aim necessitates a full treatment of the institutional context within which such analysis should take place.

This report is organised around the following structure. Firstly we outline the key concepts of sustainable tourism and introduce the institutional context within which this work is set, in particularly we outline the VisitEngland work in developing an approach to sustainable tourism that encapsulates 'Wise Growth'. We then proceed to develop a framework for evaluating sustainable tourism indicators and outline the principle previous attempts at defining sets of indicators. Within this framework, we focus on the spatial scales at which sustainable tourism indicators can be derived - this is important in terms of both the compilation or availability of data and the delivery of sustainable tourism policies at different levels; national, regional or local. It is important to recognise that priorities for sustainable tourism indicators and policy application will be different across these areas. Finally we suggest a number of sustainable tourism indicators that could be collected at the national and local scales.

The intended audience for this report are tourism professionals at national and local scales and the intention is that the report helps to inform current discourses in tourism policy that are seeking to define and measure sustainable tourism goals within the UK.

\section{Key Concepts}

In answer to the question what is Sustainable Tourism we can draw upon internationally held definitions from the UN World Tourism Organisation who define sustainable tourism as

"tourism that meets the needs of present tourists and host regions while protecting and enhancing opportunity for the future."

This definition can be elaborated upon by considering sustainable tourism not as a type of product, but rather as an ethos that underpins all tourism activities. As such, it is integral to all aspects of tourism development and management rather than being an add-on component (UNWTO, 2004)

The objective of sustainable tourism is to retain the economic and social advantages of tourism development while reducing or mitigating any undesirable impacts on the natural, historic, cultural or social environment. To achieve this we need to balance the needs of tourists with those of the destination. Clearly for many destinations the cultural or environmental quality of the locality will be a driving factor in the reasons why that location is a tourism destination in the first place. Any erosion of that 'quality' will impinge on the future sustainability of the destination. Therefore sustainable tourism has a very close linkage with sustainability in more general terms as the following points make clear, 
- sustainable tourism is also defined as a process which meets the needs of the present tourists and host communities whilst protecting and enhancing needs in the future

- sustainability principles refer to the environmental, economic, and socio-cultural aspects of tourism development, and a suitable balance must be established between these three dimensions to guarantee its long-term sustainability.

Tourism can be seen to have a special relationship (compared with other economic activities) with the environment and society. This is because of its unique dependency on quality environments, cultural distinctiveness and social interaction, security and wellbeing. On the one hand, if poorly planned or developed to excess, tourism can be a destroyer of these special qualities which are so central to sustainable development. On the other, it can be a driving force for their conservation and promotion - directly through raising awareness and income to support them, and indirectly by providing an economic justification for the provision of such support by others.

Tourism can be a tool to aid or drive regeneration and economic development as well as enhancing the quality of life of visitors and host communities. Making tourism more sustainable will contribute significantly to the sustainability of society in general.

Creating the right balance between the welfare of tourists, host communities and the environment, reducing conflict and recognising mutual dependency, requires a special approach to the management of destinations.

Therefore, the aim of Sustainable Tourism could be seen to be threefold;

1. to make optimal use of environmental resources that constitute a key element in tourism development, maintaining essential ecological processes and helping to conserve natural heritage and biodiversity.

2. to respect the socio-cultural authenticity of host communities, conserve their built and living cultural heritage and traditional values, and contribute to inter-cultural understanding and tolerance, and

3. to ensure viable, long-term economic operations, providing socio-economic benefits to all stakeholders that are fairly distributed, including stable employment and income-earning opportunities and social services to host communities, and contributing to poverty alleviation.

There are a number of terms in wider circulation which are often confused with or conflated with sustainable tourism. These terms include:

- Responsible Tourism

- Green Tourism

- Ethical Tourism

- Ecotourism

Responsible tourism is the closest definition to sustainable tourism; however it tends to refer to the consumers' choice of destination and mode of transport based on their ethical, political and racial sensitivities as well as being concerned for the environment and local culture.

Green tourism. Historically the definition of this term has been travel which is environmentally friendly or benign that in general does not concern itself with cultural or economic elements of the 
destination. Current uses of the term are becoming broader to incorporate full sustainable tourism principles.

Ethical tourism, has evolved as a term when one considers travelling to, or developing tourism in a destination where ethical issues are the key driver, e.g. social injustice, human rights, animal welfare or the environment. Ethical tourism is geared towards encouraging both the consumer and industry to avoid participation in activities that contribute or support negative ethical issues

Ecotourism, also known as ecological tourism, is a subset of sustainable tourism which focuses on ecology. Ecotourism tends to be encountered in destinations where flora, fauna, and cultural heritage are the primary attractions. The industry actively works towards conserving or improving the natural and cultural heritage through managing its own operations to help conserve the environment, organising conservation projects, offering opportunities for volunteering and educating visitors (VisitBritain, 2010).

In summation we can view sustainable tourism as tourism that is economically, socioculturally and environmentally sustainable. Additionally sustainable tourism implies that any negative sociocultural and environmental impacts are neither permanent nor irreversible. This implies a long term perspective is a necessity but also that an effective measurement framework is in place to monitor the impact of tourism from a sustainable development perspective. It is clear that this is going to involve a complex set of variables or indicators to capture the various facets of sustainable tourism.

This is a significant issue at the present time and indeed the UN World Tourism Organisation has stated that, "It is recommended that linking tourism and sustainability be considered a priority" (IRTS, 2008).

\section{The Institutional Framework}

This workstream from the TIU is by no means taking place within an institutional vacuum within the UK or more broadly through Europe and there are a number of key stages in the development of an institutional, or strategic framework, that puts sustainable tourism at the heart of the policy environment concerning tourism.

The UK Government set out their strategy for developing and promoting a sustainable approach to tourism in Tomorrow's Tourism (DCMS 1999). This promoted adopting of sustainable development principles based on Agenda 21 in all tourism strategies, whether at national, regional or local level, together with the need to develop a series of national statistical indicators to help measure progress in achieving sustainable tourism.

Following this development, the former English Tourist Council (ETC) published a sustainable strategy A Time for Action: A strategy for sustainable tourism in England (ETC 2001) in response to the challenges set down in Tomorrows Tourism. The first set of indicators, the "National Sustainable Tourism Indicators: Monitoring progress towards sustainable tourism in England" were also published in 2001 . These identified three core actions for the management of sustainable tourism: 
- To protect and enhance the natural environment and destinations;

- To support local communities and culture;

- To benefit the local economies of destinations.

Responsibility for developing the ETC's sustainable tourism indicators passed to DCMS in 2003 with the expectation of a further reporting cycle of the indicators. These indicators are now reported upon periodically by DCMS through their Indicators for Challenge (DCMS, 2009).

Recently VisitEngland has taken a lead in terms of developing a framework and strategy for a comprehensive treatment of sustainable tourism as part of the VisitEngland Strategic Framework and 'action plans'. One of the nine action plans developed to take forward the VE Strategic Framework relates to sustainable tourism and is being developed through the Sustainable Tourism Action Group or STAG, led by VisitEngland. The vision for STAG is to "grow tourism responsibly in a finite world, creating resilience and prosperity for all". STAG have coined the phrase "Wise Growth' which is used to illustrate the linkage between the Strategic Framework growth target and the principles of sustainable development.

In the action plan developed by STAG a number of underlying principles of Wise Growth, drawn from a range of globally recognised definitions, are set out which characterise Wise Growth in tourism as:

Inclusive: visitor experiences are fun, inspirational, safe, open and accessible to all with no discrimination based on gender, race or disability.

Engaging: involving local residents in tourism development through working relationships, consultation and cooperation.

Well-being: tourism activities strengthen and sustain the quality of life of the communities in which they take place by improving access to local resources and amenities for residents.

Caring: the cultural heritage of places, the authenticity and distinctiveness is protected or enhanced through preserving traditions and local culture for both residents and visitors.

Distinctive: the quality of the urban, coastal and rural environment is maintained or enhanced without physical or visual degradation.

Fun and appealing: capitalise on the enjoyment of England's natural and built environments, habitats and wildlife but ensure these are not damaged in the process.

Viable: champion local businesses that operate successfully and responsibly over the long-term. Create and strengthen the number and quality of local jobs supported by tourism activities, including salary, conditions and availability. Ensure local residents benefit from the tourism activity they host, especially by maximising visitor spending retained in the local economy.

Efficient: visitors and businesses use scarce and non-renewable resources wisely; visitors and businesses seek to minimise pollution, especially from transport, and reduce waste from all tourism activity. 
Wise Growth, therefore, is based on three fundamental components:

- Responsible growth, in a finite world. Taking personal and collective responsibility to ensure tourism grows with respect for the boundaries and priorities of all its stakeholders.

- Creating resilience. Tourism that is designed to last, that is flexible and responsive to the environment in which it takes place and which engages and respects the needs of all stakeholders.

- Prosperity for all. Wise Growth results in long term sustained development for all. It is not necessarily quick growth or growth at all costs. It is tourism that is developed within our means (economically, socially and environmentally) and which ensures that overall quality of life is improved by our actions.

It is felt that by identifying the causes of tourism's positive and negative impacts it should be possible to systematically exploit opportunities for change and improvement. It is suggested that this can be achieved through understanding of the relationships that are at the heart of Wise Growth in tourism. This cooperative approach means that wherever tourism takes place, four key stakeholders groups must always be engaged in its management and development:

- Visitors: without whom there would be no tourism

- Environment: the physical area in which tourism takes place

- Residents: who live where any tourism takes place

- Businesses: the primary players who deliver tourism activity

The TIU is a delivery partner in this action and is charged with developing one simple meaningful indicator on the impacts of tourism for these four stakeholder groups referred to as VERB hereafter. In terms of expected outcomes from this work, STAG would like to see;

1. Four agreed indicators to benchmark and measure performance (This is more difficult than it might seem)

\section{Report on indicators on an annual basis linked to the review of the action plan}

3. Assess the effectiveness of foot printing tools, such as REAP Tourism, to complete a life cycle analysis of English visitors. This would help establish the characteristics and contributing factors to a visitors' footprint enabling planning and modelling to take place. This will enable a greater understanding of impacts of tourism from the supply and demand side to facilitate more focused development plans.

As well as this UK and England context there is an important international context to the development of sustainable tourism. We have already seen the importance attached to this area by UNWTO in their recommendations on tourism statistics but it is also high on the agenda in the EU. In this European context there has been much debate about developing a set of sustainable tourism indicators through the work of the Tourism Sustainability Group which was set up by the European Commission in 2004. The Group comprises individuals from international bodies, member state governments, regional and local authorities, the tourism industry, professional bodies, environmental organisations, trade unions and research and educational bodies, who have expertise and experience in the sustainability of tourism. 
We have considered in depth the suite of indicators proposed by the TSG in detail in the interim report for this workstream and we return to them again later in this report. The indicators have been assessed by the EDEN destinations in Europe and have, in the UK, been adopted (to some extent) by DP:UK in their baseline statements. It is important to stress that the TSG indicators are targeted at the destination, or local level, and the level of detail could not be expected to be replicated at the national level. Given the long process of formulating the TSG indicators and their broad acceptance across member states involved in the process (as well as input from the UK), it is sensible to treat the TSG indicators as the basis for developing a set of local sustainable tourism indicators.

\section{A Framework for Developing Sustainable Tourism Indicators}

In this section we provide a framework for the selection of sustainable tourism indicators. This has drawn upon best practice as identified in the review of previous ST indicator development detailed in the interim report to this workstream, and particularly draws on the reporting of the Cairngorms National Park sustainable tourism indicators carried out by the Macaulay Institute.

There have been a number of stages in this research process, and this is highlighted in Figure 1 below. Aside from the review of previous best practice and the strategic context within which the work is set, detailed already in this report and the interim report, it is important to formalise the selection process for indicators, including their appraisal and communication, as an important step towards final adoption.

Figure 1: Overview of the Research Process 


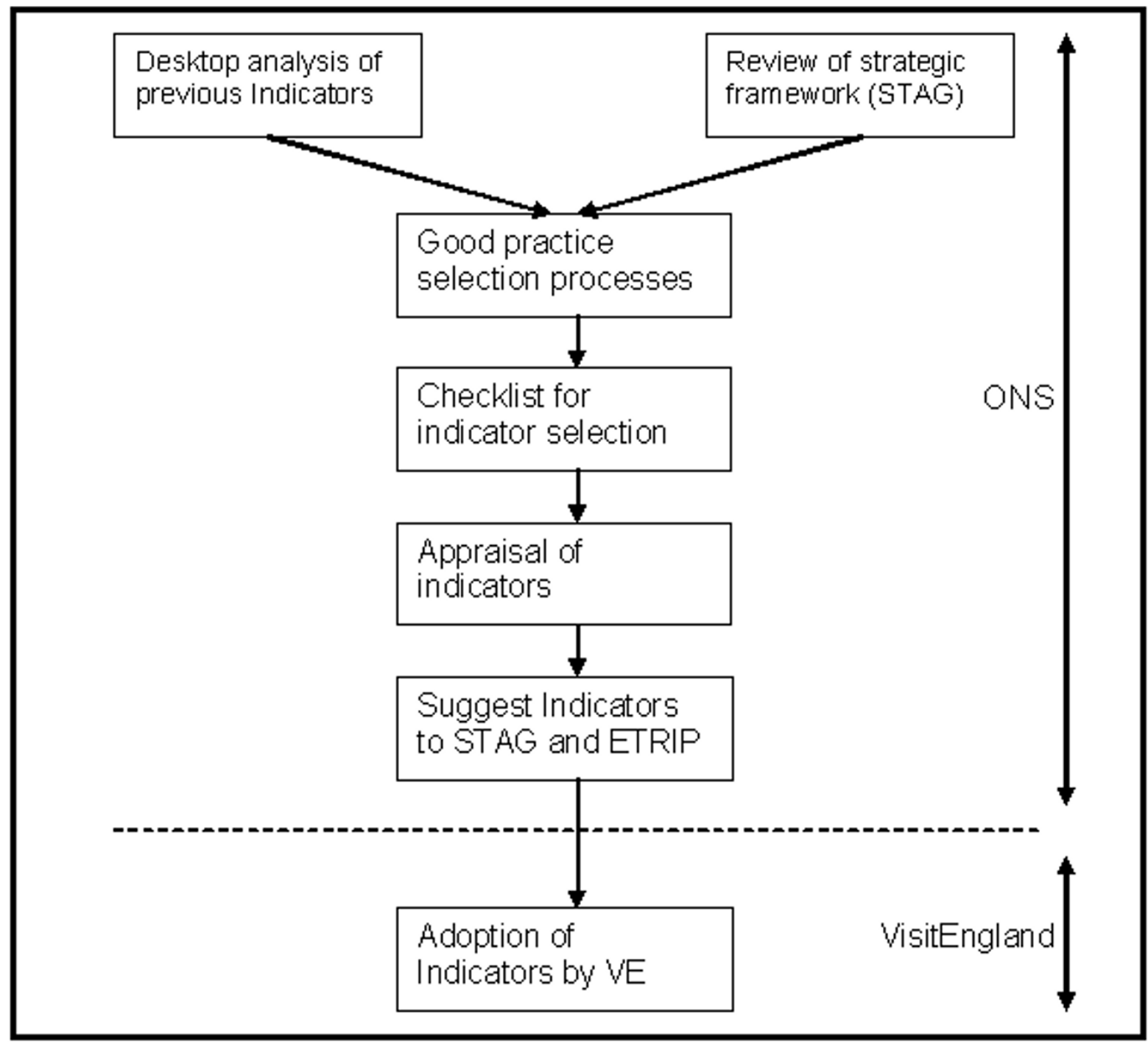

Blackstock et al (2006) in a research report for the Cairngorms National Park use an indicator cycle to help explain indicator development, shown in Figure 2. This implies that any individual indicator should normally be seen as a component part of a wider group of indicators possessing a distinct identity - the Tourism Sustainability Group indicators previously mentioned are a good example of this approach.

Figure 2: The Indicator Cycle 


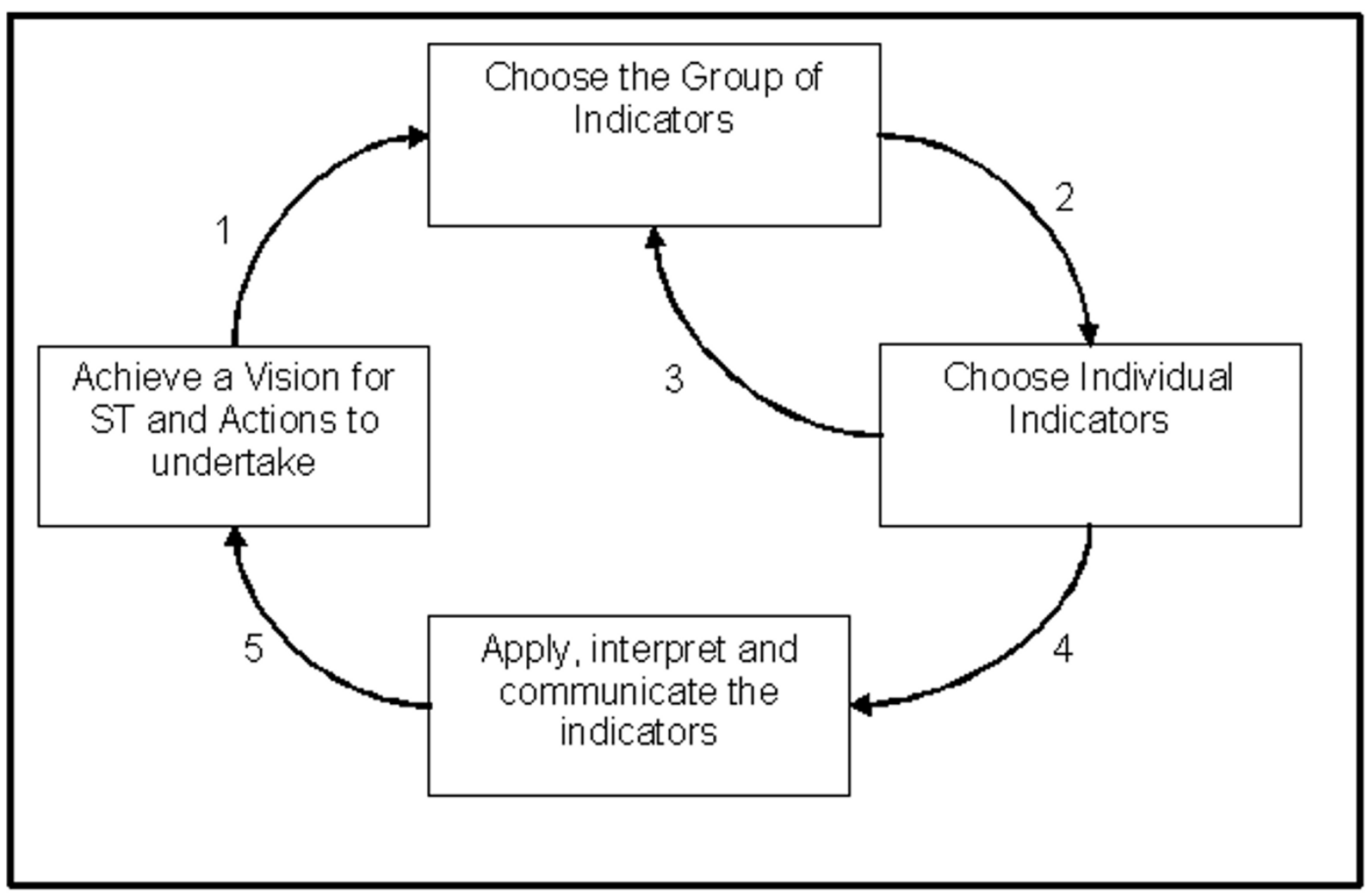

The first stage of this process is to select the broad groupings for indicators. This grouping is selected using a combination of strategic objectives, stakeholder consultation and in our case this has already been achieved through the VisitEngland's development of the Wise Growth concept and the identification of the VERB (Visitors, Environment, Residents, Businesses) stakeholder groups.

Once the overall group of indicators is established (stage one), the individual indicators can be selected (stage two). These then have to be reassessed against the overall group criteria (stage three). The chosen indicators are applied and the results interpreted and communicated (stage four). The results should be checked against the original objectives and action plans for the strategy, and any revisions (to the strategy, actions or to the indicators) carried out (stage 5).

\section{A Framework for Identifying Indicators}

One method that is often employed in the development of indicators (for example, used by the European Environment Agency in developing their Environmental Indicator Set) is the 'DriversPressure-State-Impact-Response' (DPSIR) framework. This is used as an example to illustrate how a framework can provide an overview of the different dimensions of Sustainable Tourism. 


\section{Figure 3: The DPSIR Framework}

\section{The DPSIR Framework}

Drivers and Pressure data allows predictions of what might happen in the future.

State data shows 'where we are' but also how things are changing.

Impact data shows why changes matter - what are the positive or negative effects of the current state on the qualities we are seeking to protect?

Response data measures what policies are put in place and whether they are having their desired effect.

Adopting the DPSIR framework requires understanding what the individual indicators are measuring in terms of whether they are a measure of 'drivers and pressures', 'state', 'impact' or 'response' with the aim of achieving a balanced assessment of all these areas. Table 1 illustrates the current sustainable tourism indicators employed by DCMS and shows that they provide a good foundation for the key themes but there are gaps when applied to the DPSIR framework (Table 1 can be found in the downloadable excel file associated with this report). Thus the framework helps in highlighting these gaps which can potentially be filled as we move forward with this process.

The framework aims to encourage reflection on different dimensions of sustainable tourism and to ensure that they are all being monitored. However, many indicators could have been allocated to more than one column in table 1, depending on how the results are interpreted (e.g. a number could represent a state, but changes in states over time could be either a pressure or an impact). As an example, we can see this graphically for Indicator 3 'Transport used on holiday trips' which could be regarded as measuring the current state of play or, alternatively, driving a change the current state. The framework requires that the purpose of the indicator is made explicit and is clearly linked to the dimension it is supposed to be measuring.

Any framework has an implicit world view attached to it. The DPSIR framework assumes a world of linear, predictable and reversible relationships. Whilst a framework helps provide coherence to choices being made, and to illustrate gaps in coverage, no framework is perfect and the assumptions underpinning the framework must be acknowledged (Blackstock et al, 2006). The DPSIR approach is one that we return to in the final section of this report when we suggest a set of indicators for use at the national or local levels.

The DPSIR framework is adopted here as an attempt to determine what impact particular indicators are trying to monitor, in other words are indicators aimed at monitoring the current state of tourism activity across the stakeholder groups, for example, or are they more concerned with trying to identify, for example, responses to that situation that may lead to changes in the state. This provides us with a context that future work from the TIU will seek to test using data at the national or local level. 
There are two main stages in the selection of indicators and these are based around the identification of groups of indicators and the selection of the individual indicators within those groups. The selection process for the groups of indicators is shown in Figure 4 and in some ways this is made easier by the fact that a clear framework is in place through the Wise Growth agenda and the key stakeholder groups that make up VERB have been identified. Figure 4 highlights where the identification of a framework for analysis fits into this process.

\section{Figure 4: Selecting Groups of Indicators}

Figure 4: Selecting Groups of Indicators

\begin{tabular}{|l|l|}
\hline Identify key themes to be covered & $\begin{array}{l}\text { Refer to VisitEngland } \\
\text { Sustainable Tourism } \\
\text { Action Group reports } \\
\text { (VERB) }\end{array}$ \\
\hline \begin{tabular}{|l|l|} 
Check the themes have a clear and \\
logical identity for reporting purposes
\end{tabular} & $\begin{array}{l}\text { Discussion, consultation, } \\
\text { expert advice on STS }\end{array}$ \\
\hline \begin{tabular}{|l|l|} 
Identify suitable framework \\
within the theme and the framework
\end{tabular} & $\begin{array}{l}\text { 'Drivers - Pressure - } \\
\text { State - Impact - } \\
\text { Response' Framework }\end{array}$ \\
\hline $\begin{array}{l}\text { Calance of } \\
\text { ervironmental, economic } \\
\text { and social and DPSIR } \\
\text { measure the topics identified }\end{array}$ & $\begin{array}{l}\text { Refer to existing } \\
\text { indicator sets and } \\
\text { examples of 'good } \\
\text { practice' }\end{array}$ \\
\hline
\end{tabular}

The next stage in the process is to identify individual indicators to populate the target groups identified at the previous stage which is shown in Figure 5. There are some practical issues involved in this process such as appraisal of the spatial scale and timeliness of the indicator or whether, indeed, it is easily measurable. It is clear, however, that there is a significant consultative process implied in this process and while much progress has been made in that area with consultation carried out with the English Tourism Intelligence Partnership and the Sustainable Tourism Action Group, this remains an area where on-going consultation is crucial. Whilst we may suggest possible 
indicators in this report, a final set of indicators would need to be approved by those charged with developing policy for sustainable tourism.

Figure 5: The Selection Process for Individual Indicators 
Figure 5: The Selection Process for Individual Indicators

Is the indicator relevant to tourism delivery partners?
How does it relate to the policy framework for ST
Does the indicator clearly relate to sustainable tourism outcomes?
In terms of Visitors,

Environment, Residents, or Businesses

What are assumptions about link with ST. What is significance of a +ve or -ve change?

Is it an indicator that can be agreed by different levels of tourism governance as reflecting $\mathrm{ST}$

Is change in the indicator easily interpreted?
Is data comparable over time period (e.g. months, years) and areas, (e.g. LAs)

Is data available and collected in a reliable fashion?

Graphic presentation, in map fom or traffic light
ONS, VisitEngland,

STAG etc.

\section{system}

Who will take responsibility for collecting/ interpreting/ communicating the data?
Can the indicator be measured? (if the answer is NO then a decision is needed as to whether data should be collected)

How will the results be presented?
Is the process for choosing, measuring and using each indicator clear? 


\section{The Spatial Scale: A 'two-tier' approach}

The spatial scale at which indicators are analysed and reported is of key importance in this work. There has to be an awareness of the national context within which this work is set and how it is important to monitor the sustainable development of tourism at this level. That said, it is clear that for tourism the challenge is in delivering sustainable or wise growth at the local level and therefore a set of indicators that monitor progress against wise growth at this level is desirable. We suggest that a 'two-tier' approach is needed with a set of indicators at the national level to monitor the progress of wise growth against the four stakeholder groups that comprise VERB, with a complementary set of indicators (some of which may not currently be available in all areas) that monitor local progress against the aims of wise growth. Ideally we would be able to disaggregate national indicators to the desired local level but this will not always be possible and some local collection of indicators is likely to be necessary, see Figure 6 below.

Figure 6: A 'two Tier' approach

Figure 6: A 'two tier' approach

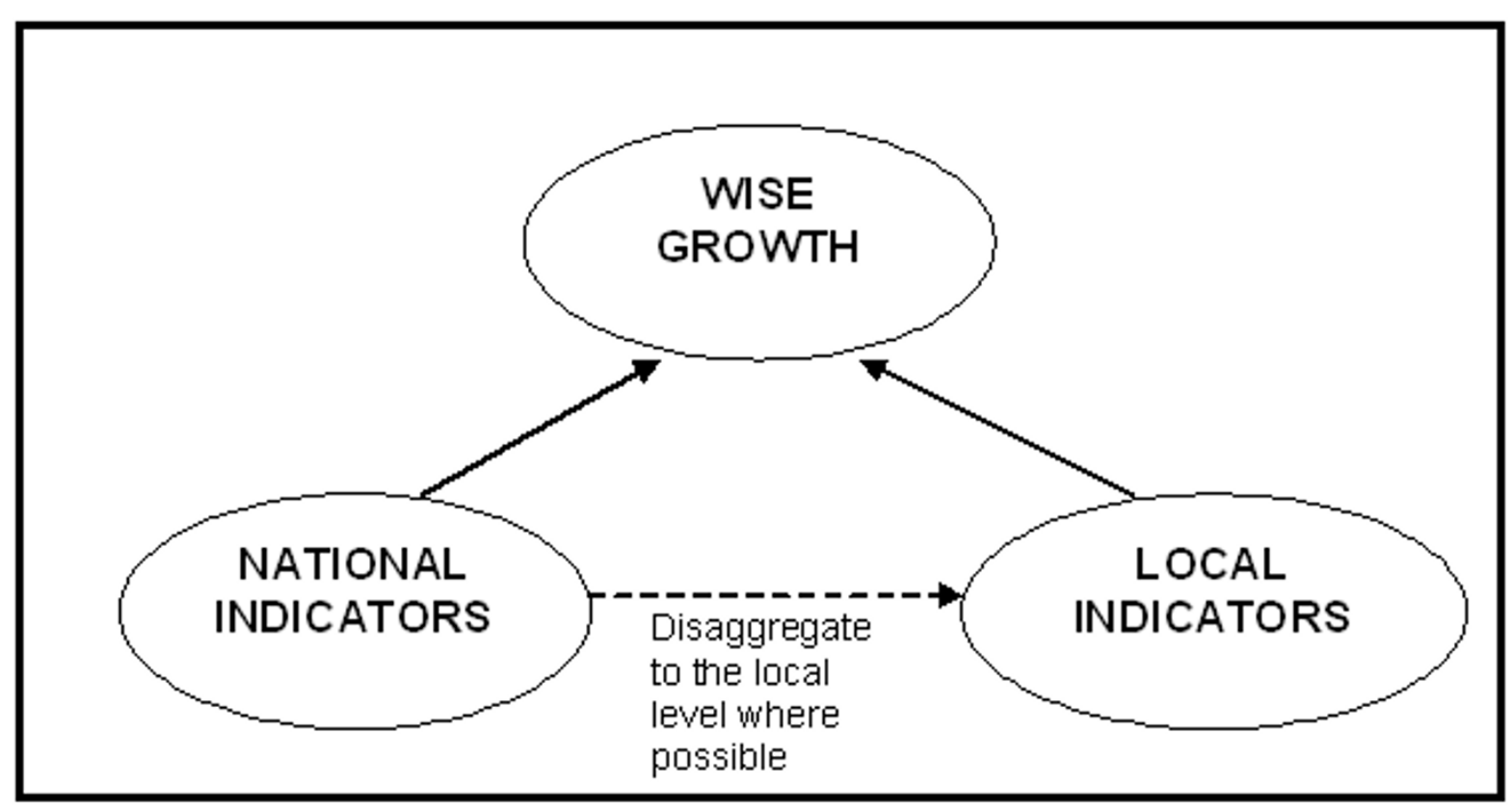


In this section we assess the indicators that can be collected at the national level and local level and highlight where there may be clear gaps in data availability. Some indication of the source and frequency of available indicators is also provided. In Table 2 we highlight those types of indicators that could be applied across the four stakeholder groups of VERB at the national level. In Table 3 we return to the EU's Tourism Sustainability Group's set of sustainable tourism indicators and attempt to apply these to the VERB stakeholder groups. Table 2 and 3 are available in the downloadable excel file associated with this report.

\section{Some Options for the Presentation of Findings}

An important area that we need to consider moving forward is how best to present the findings of this research. In some ways this should be user-driven, but there are some basic principles of presentation or visualisation that we should try to adopt. We should also consider the potential of presenting results for different types of locality, for instance to highlight the difference between urban and rural manifestations of sustainable tourism indicators, or to consider different classifications of areas.

\section{Urban and Rural Classifications}

It could be helpful to present the indicators on the basis of whether an area is urban or rural in nature. The reason for this is that certain aspects of Wise Growth and the stakeholder groups that make up VERB may well play out differently across rural and urban areas, for instance those relating to the environment or resident views of tourism. There is in place a standard Local Authority (LA) classification of urban and rural areas in England (slightly different classification are in place in Scotland and Wales). The LA Classification was introduced in 2005 as a Department for Environment, Food and Rural Affairs (DEFRA) initiative and was delivered by the Rural Evidence Research Centre at Birkbeck College (RERC). Many statistics relating to sustainable tourism are only available at Local Authority level (in a best case scenario) so this is probably the most pertinent classification in this case (there are urban-rural classifications for Output Areas but we don't cover those in this context). In order to differentiate between Rural and Urban for these statistics it is necessary to classify the LAs based on their rurality.

There are six urban/rural classifications; defined as follows: 
1. Major Urban: districts with either 100,000 people or 50 per cent of their population in urban areas with a population of more than 750,000

2. Large Urban: districts with either 50,000 people or 50 per cent of their population in one of 17 urban areas with a population between 250,000 and 750,000

3. Other Urban: districts with fewer than 37,000 people or less than 26 per cent of their population in rural settlements and larger market towns

4. Significant Rural: districts with more than 37,000 people or more than 26 per cent of their population in rural settlements and larger market towns

5. Rural-50: districts with at least 50 per cent but less than 80 per cent of their population in rural settlements and larger market towns

6. Rural-80: districts with at least 80 per cent of their population in rural settlements and larger market towns

National Statistics 2001 Area Classification of Local Authorities

An alternative approach to looking at urban and rural characteristics could be to employ the 'National Statistics 2001 Area Classification of Local Authorities' which is based upon 2001 Census data. This represents a powerful and effective way of summarising the complexity of census data. It provides a simple indicator of the characteristics of an area and of the similarity between areas, for comparative or targeting purposes, and as a variable for analysis with other data.

The classification groups authorities into a three-tier hierarchy of supergroups, groups and subgroups. There are eight supergroups, thirteen groups and twenty four subgroups. For most purposes the thirteen groups will be the optimum but if required the supergroups or subgroups can be used. The eight supergroups and thirteen groups are shown graphically below in Figure 7 .

Figure 7: Supergroups and Groups 
Figure 7: Supergroups and Groups

Supergroup

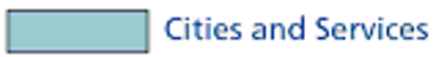

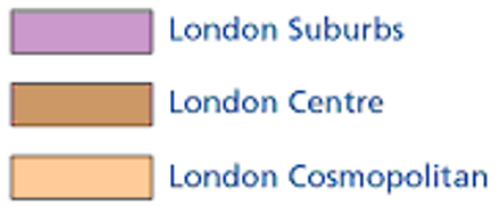

Prospering UK

Coastal and Countryside

Mining and Manufacturing
Group (no of subgroups)

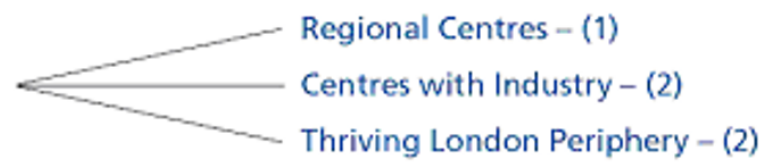

London Suburbs - (2)

London Centre - (2)

London Cosmopolitan - (2)

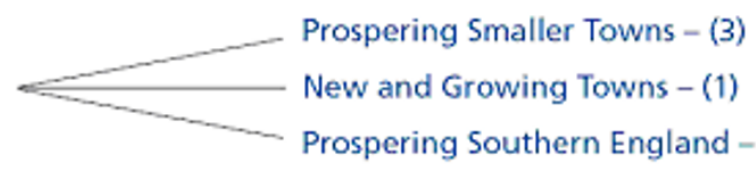

(1)

Coastal and Countryside - (3)

Industrial Hinterlands - (2)

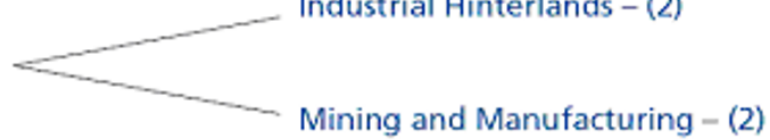

Mining and Manufacturing - (2)

Northern Ireland Countryside - (1)

The classification was produced using the statistical technique of 'cluster analysis'. Essentially there were four stages in devising the classification 1) selecting variables to perform the analyses, 2) standardising these variables for analyses, 3) the Cluster Analysis itself, and 4) labelling of the resulting clusters to create a classification hierarchy. For any classification the result will depend upon the variables used in the analysis. The main objective when selecting the variables for this classification was to choose the minimum number that would adequately represent the main dimensions in the 2001 Census data. These have been defined as: demographic structure, household composition, housing, socio-economic character, employment and industry sector.

Variables were selected from the 2001 Census Key Statistics tables which are accessible to the public. The number of possible variables was reduced to 42 which were then used to produce the classification. This reduction process removed highly correlated variables ensuring certain population characteristics were not over represented but retained those that allowed the maximum differentiation between areas. 
The cluster analysis place each area in a group with the other areas to which it was most similar in terms of the 42 variables selected. This enables areas to be classified according to their particular combination of characteristics.

These different classifications highlight potential areas for future representation of the sustainable tourism indicators. When this work moves to the next phase of analysing agreed upon indicators then the TIU will examine both potential classifications as possible means of presenting the sustainable tourism indicator data. We now turn our attention to recommending some options for sustainable tourism indicators aimed at taking forward this process.

\section{Recommendations}

In this section we set out some recommendations for developing sustainable tourism indicators in line with our simplified two-tier approach and adopting the DPSIR framework. We attempt to, firstly, identify a set of core indicators that are already collected and therefore relatively straightforward to adopt now, and secondly, to identify indicators that would be potentially beneficial but that would probably need some development work to achieve a consistent coverage either nationally or locally in the UK - these we would term aspirational.

In tables 4 and 5, we highlight the core and aspirational sustainable tourism indicators within a DPSIR framework at the national and local level respectively. This should help reveal areas where we perhaps need to think of alternative indicators and that may emerge from the consultation process as well. Within Tables 4 and 5 core indicators are in bold and aspirational indicators are in italics. Tables 4 and 5 can be accessed from the downloadable excel file associated with this report.

The suggested indicators presented in Table 4 and 5 have been consulted upon and there are a number of issues that have been raised about both the core and aspirational sustainable tourism indicators at the national and local levels that we now discuss.

- There have been positive comments about presenting the sustainable tourism indicators in terms of the VERB stakeholder groups but less support for the use of the DPSIR framework which is seen as perhaps over complicated. Our view is that this framework has been helpful in thinking about the potential impact that the indicators are designed to measure in terms of the 'stages' of sustainable tourism but, clearly, once a set of final sustainable tourism indicators is agreed we accept that they should be presented in a straightforward manner possibly just related to the VERB stakeholder groups.

- A second issue is that we need to ensure that the VERB stakeholder groups are not taken in isolation but rather that we attempt to determine a balanced view that considers how a benefit to visitors or businesses may have a disbenefit to the environment and community. This will be considered and addressed in the second phase of this work where we undertake analysis of indicators. In undertaking the analysis we will need to consider how we interpret and balance these conflicting impacts of the indicators. This will be a crucial element of the ongoing work.

- There is a suggestion that we need to focus on some key indicators as a smaller amount of good quality data would be preferable to a set of comprehensive and perhaps burdensome set of indicators that would, perhaps, have limited impact. We would fully support this and 
the indicators presented in Table 4 and 5 should be seen as a first step towards refining and reducing the set of indicators. This will be driven to some extent by the data analysis stage of the research which should help identify the indicators that are most effective in monitoring change, and also identify those that overlap.

- Finally, it has been stressed that the indicators need to be able to measure impact and that there perhaps needs to be more focused on measureable items such as the $\mathrm{KwH}$ of energy saved or litres of water saved rather than whether businesses are taking part in a particular sustainable tourism initiative. This would be a preferable measure but there may be a trade off between what data is available and can be collected and analysed, not only as part of this work but by local or national tourism organisations. Certainly this is an area worthy of further attention as the work proceeds.

In conclusion we present the suggested sustainable tourism indicators here in table 4 and 5 as core or aspirational but clearly there is still significant work to be done in terms of collecting and analysing information relating to these indicators to address some of the issues raised by consultees and to start to move towards a refined set of sustainable tourism indicators to inform the progress of Wise Growth. This will form the next phase of this work programme from the TIU.

\section{References}

Blackstock et al, (2008) A framework for developing indicators of sustainable tourism. Macaulay Institute.

DCMS (2009) Indicators for Challenge, HMSO

EC (2007) ACTION for MORE SUSTAINABLE EUROPEAN TOURISM Report of the Tourism Sustainability Group

European Commission (2004) Methodological Work on measuring the sustainable development of tourism. Luxembourg

UNWTO (2004) Indicators for Sustainable Tourism: A Guidebook, Madrid 